\title{
At-sea movements of wedge-tailed shearwaters during and outside the breeding season from four colonies in New Caledonia
}

\author{
Henri Weimerskirch ${ }^{1, *}$, Sophie de Grissac ${ }^{1,2}$, Andreas Ravache ${ }^{3,4}$, Aurélien Prudor ${ }^{1}$, \\ Alexandre Corbeau ${ }^{1}$, Bradley C. Congdon ${ }^{5}$, Fiona McDuie $^{5}$, Karen Bourgeois ${ }^{3}$, \\ Sylvain Dromzée ${ }^{3}$, John Butscher ${ }^{6}$, Christophe Menkes ${ }^{4}$, Valérie Allain ${ }^{7}$, \\ Eric Vidal $^{3,4}$, Audrey Jaeger ${ }^{8}$, Philippe Borsa ${ }^{9}$
}

\footnotetext{
${ }^{1}$ Centre d'Etudes Biologiques de Chizé, UMR 7372 du CNRS-Université de La Rochelle, 79360 Villiers-en-Bois, France

${ }^{2}$ Swansea Laboratory for Animal Movement, Department of Biosciences, Swansea University, Swansea SA2 8PP, UK

${ }^{3}$ Institut Méditerranéen de Biodiversité et d'Ecologie marine et continentale (IMBE), Aix Marseille Université, CNRS, IRD, Avignon Université, Centre IRD Nouméa - BP A5, 98848 Nouméa Cedex, New Caledonia

${ }^{4}$ UMR ENTROPIE (IRD-Université de La Réunion-CNRS), Laboratoire d'Excellence Labex-CORAIL, Institut de Recherche pour le Développement (IRD), BP A5, 98848 Nouméa CEDEX, New Caledonia, France

${ }^{5}$ College of Science and Engineering, James Cook University, Cairns, QLD 4878, Australia

${ }^{6}$ IRD-Sorbonne Universités (UPMC, Univ Paris 06)-CNRS-MNHN, LOCEAN Laboratory Centre IRD de Nouméa, 98848 Nouméa Cedex, France

${ }^{7}$ Pacific Community (CPS), 98848 Nouméa, New Caledonia

${ }^{8}$ UMR ENTROPIE, UMR 9220 du CNRS- IRD-Université de La Réunion, 15 Avenue René Cassin, BP 92003, 97744 Saint-Denis, La Réunion, France

${ }^{9}$ UMR ENTROPIE, IRD, 34394 Montpellier, France
}

\begin{abstract}
The wedge-tailed shearwater (WTS) population of New Caledonia is one of the largest in the world, yet its biology and foraging ecology are poorly known. We studied WTS from 4 colonies in New Caledonia. We examined foraging behaviour and habitats using GPS receivers and light sensors during and outside the breeding season, respectively, and compared our findings with those from other WTS populations worldwide. During breeding, New Caledonian WTS alternated short foraging trips close to the colony over the lagoon, or off the reef edge, with longer trips over distant, deep waters. Whereas neighboring colonies overlapped at sea, especially during short trips, there was a clear separation of foraging zones between the pairs of colonies located in the southern versus northwestern parts of New Caledonia. Although WTS actively foraged and commuted to foraging zones during the day, they mainly returned to the colony or rested at night, indicating that they feed mainly during the day. Active foraging did not take place in more productive areas, suggesting that it may instead be related to the presence of sub-surface predators. Outside the breeding season, birds from 3 colonies had similar trans-equatorial migratory behaviour. All left New Caledonia at the same time of the year with a fast, northeasterly movement and wintered over deep waters in the same sector of the northwestern tropical Pacific Ocean. At overwintering sites, they spent most of their non-foraging time presumably sitting on the water, especially at night, making a slow westward movement before returning to New Caledonia. WTS from New Caledonia forage over warm, oligotrophic deep waters throughout their life cycle, and the species appears to have a flexible foraging strategy adapted to the various environmental conditions encountered across its wide tropical range.
\end{abstract}

KEY WORDS: Seabird · Geolocator · GPS · Trans-equatorial migration · New Caledonia

*Corresponding author: henri.weimerskirch@cebc.cnrs.fr
(C) The authors 2020. Open Access under Creative Commons by Attribution Licence. Use, distribution and reproduction are unrestricted. Authors and original publication must be credited. 


\section{INTRODUCTION}

The tropical marine environment is on average less productive and has lower seasonal variability than waters at higher latitudes. Marine mesopredators such as seabirds have evolved specific foraging strategies to cope with these conditions, such as reduced flight costs and unseasonal breeding (Ashmole 1971, Spear et al. 2007, Catry et al. 2009a). In particular, many species rely on sub-surface predators such as tunas to facilitate access to prey (Au \& Pitman 1986, Jaquemet et al. 2004). The wedge-tailed shearwater Ardenna pacifica (WTS) is a very abundant species that forages over oligotrophic, tropical waters in both the Indian and Pacific Oceans. During the breeding season, WTS forage over oceanic as well as shallower waters (McDuie et al. 2015, McDuie \& Congdon 2016). Similar to other petrels and albatrosses at higher latitudes (Weimerskirch et al. 1994), when surrounded by low-productivity, near-colony foraging environments, adult WTS use a bimodal foraging strategy whereby they alternate short trips close to the colony to provision their offspring with long trips to distant, more profitable foraging locations to obtain food primarily for themselves (Congdon et al. 2005, McDuie et al. 2015, McDuie \& Congdon 2016). This strategy is generally assumed to enable individuals relying on low-productivity or distant waters to provision the offspring at sufficient rate (Weimerskirch et al. 1994, Weimerskirch 1998). However, WTS have also been reported to use a unimodal foraging strategy at sub-tropical sites such as Hawaii (Baduini 2002) and Aride Island, where birds make short trips over the Seychelles plateau (Cecere et al. 2013). WTS also may switch between unimodal and dual foraging strategies at other sites in response to seasonal changes in resource availability (e.g. Lord Howe Island; Miller et al. 2018). This switching behaviour can result in individuals from 2 distant colonies in the subtropical and tropical Pacific overlapping at sea during long trips in some years, but not in others (Miller et al. 2018). Combined, these results indicate a flexible foraging strategy that varies according to breeding site in response to local variations in resource availability.

Many Procellariiformes undertake long migrations during the non-breeding season (Shaffer et al. 2006) and use specific migratory routes to take advantage of the oceanic wind regimes (Felicísimo et al. 2008), while others leave the breeding grounds and make long-distance dispersive movements. For example, in the Indian Ocean, WTS breeding in the equatorial zone disperse to tropical waters throughout the oceanic basin (Catry et al. 2009b); those breeding in western Australia move northward to reach the equatorial zone (Surman et al. 2018). In contrast, WTS breeding in the southern Great Barrier Reef undertake a directed trans-equatorial migration and spend the non-breeding season in the tropical waters of the northern hemisphere (McDuie \& Congdon 2016). Thus WTS show a variety of strategies during and outside the breeding season, most likely in response to variations in the local environmental conditions they encounter throughout their annual life cycle.

New Caledonia is located in the middle of a largescale, north-south temperature and salinity gradient influenced in the north by the equatorial Warm Pool and the South Pacific Convergence Zone, and in the south by the cool and highly productive Tasman Sea. The waters around New Caledonia are oligotrophic, especially in the upper layers, with low nutrient and low primary production (Ceccarelli et al. 2013, Menkès et al. 2015, Payri et al. 2019). Yet New Caledonia hosts one of the largest populations of WTS in the world, with hundreds of thousands of pairs breeding on the mainland and the neighbouring islands and islets of its southern lagoon (PandolfiBenoit \& Bretagnolle 2002). The presence of this very large population of WTS located in low-productivity waters may entail a potentially high level of intraspecific competition among individuals, conditions that can lead to specific foraging behaviours that reduce competition, such as longer foraging ranges (Ashmole halo effects; Ashmole 1963), or to the separation of foraging zones between colonies (Lewis et al. 2001). Segregation between colonies, considered to result from inter-colony competition, is itself a function of colony size, foraging range and productivity (Bolton et al. 2019). Thus, studying geographic overlap in foraging areas between colonies within a large population that relies on poor surrounding tropical waters is of particular interest when considering the evolution of segregation. Compared to highly productive temperate or polar regions, where segregation has been mainly studied (Bolton 1995), it can be predicted that in poor tropical waters segregation between colonies should be maximal. In addition, how this regional population deals with presumed reduction of resources during the winter remains unknown.

Here, we studied foraging behaviour during both the breeding and the migratory periods in WTS from 4 colonies in New Caledonia to evaluate how local conditions may sustain such large numbers of breeding individuals. We examined whether the population uses a bimodal foraging strategy to cope with presumably reduced near-colony food availability 
and/or intra-specific competition, and whether the foraging areas used by different colonies overlap (Bolton et al. 2019). To examine this, we equipped WTS with miniaturized GPS during 2 different breeding seasons in 4 colonies. We also studied the movements of WTS from 3 of the same populations during the non-breeding season using geolocators (GLS), to examine whether New Caledonian birds use trans-equatorial migration, or a dispersive behaviour, and to compare the conditions encountered during the non-breeding season with those during the breeding season.

\section{MATERIALS AND METHODS}

\subsection{Tracking of breeding adults}

Breeding WTS were tracked from 4 colonies, 2 on the mainland and 2 on offshore islets of New Caledonia, in 2014 at Temrock $\left(21.560^{\circ} \mathrm{S}, 165.269^{\circ} \mathrm{E}\right)$ and in 2017 at Pindaï $\left(21.354^{\circ} \mathrm{S}, 164.954^{\circ} \mathrm{E}\right)$, Ile aux Canards $\left(22.313^{\circ} \mathrm{S}, 166.436^{\circ} \mathrm{E}\right)$ and Ilot Mato $\left(22.550^{\circ} \mathrm{S}\right.$, $166.792^{\circ}$ E). Temrock and Pindaï are located $40 \mathrm{~km}$ apart on the central western coast of the mainland of New Caledonia, and Mato and Canards are small islets located $30 \mathrm{~km}$ apart in the southern lagoon off the southern part of New Caledonia (Fig. 1). About $200 \mathrm{~km}$ separate the northern colonies from the southern ones (Fig. 1). WTS breed in the colonies from December (egg-laying) to April, when chicks fledge.

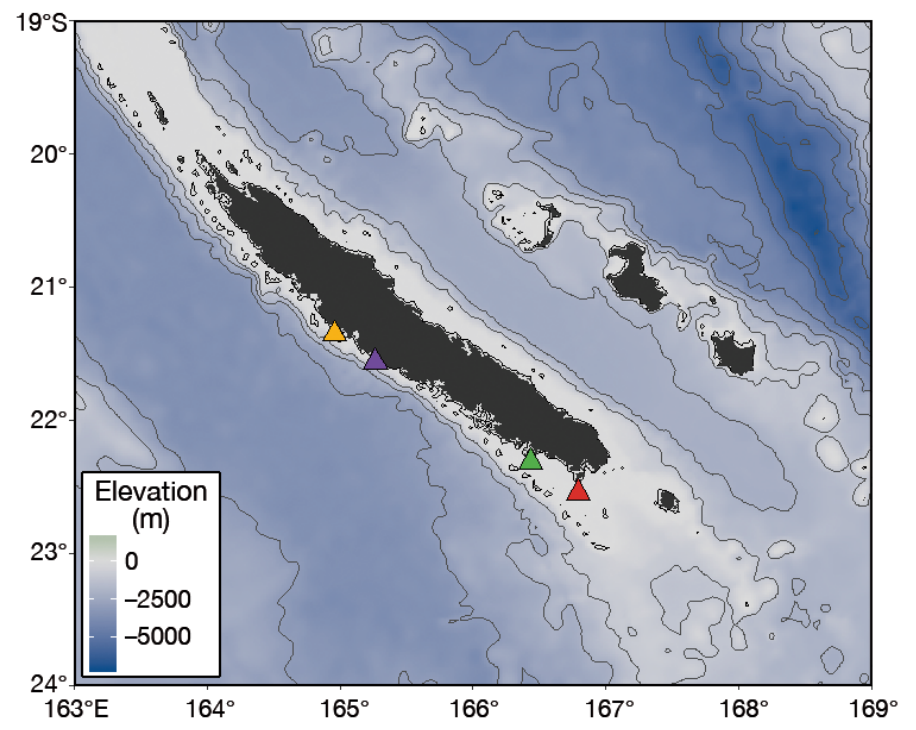

Fig. 1. New Caledonia, showing the location of the 4 wedgetailed shearwater (WTS) colonies: Pindaï (yellow), Temrock (purple), Canards (green) and Mato (red)
The deployments of GPS receivers took place between 25 February and 14 March 2014 at Temrock and between 8 March and 30 April 2017 at the other 3 colonies. Breeding adults provisioning their chicks were equipped with miniaturized GPS receivers. Depending on the model and on the weight, these devices were mounted on adults either at the base of the tail on 3 feathers (for those GPS receivers $>11 \mathrm{~g}$ ) with a single strip of adhesive Tesa ${ }^{\mathrm{TM}}$ tape (Beiersdorf), or on back feathers (GPS receivers $<11 \mathrm{~g}$ ) with strips of adhesive Tesa ${ }^{\mathrm{TM}}$ tape. Devices were deployed on adults upon their exit from the nest following chick feeding and removed after one or several trips at sea. In 2014, we used battery-powered i-gotUTM GT-120 GPS loggers (Mobile Action Technology). GPS receivers (weight $\sim 12 \mathrm{~g}$, dimensions $42 \times 23 \times 10 \mathrm{~mm}$ ), after replacing the battery (90 to $120 \mathrm{~mA} \mathrm{~h}$ ), were repacked in $50 \mathrm{~mm}$ clear heatshrink wrapping (McDuie et al. 2018). In 2017, we used $5 \mathrm{~g}$ nano-fix GEO+RF (Pathtrack), $6 \mathrm{~g}$ Pica (Ecotone), $12 \mathrm{~g}$ Axytreck (TechnoSmart) and $5 \mathrm{~g}$ PinPoint 75 (Lotek) GPS receivers. WTS weigh between 320 and $470 \mathrm{~g}$, and the weight of the loggers fell within, or close to within, the accepted limit of $3 \%$ of body weight for device deployment on seabirds (Phillips et al. 2003). Details on deployment dates, sample sizes and equipment used at each colony are given in Table 1.

\subsection{GPS tracking}

\subsubsection{Data preparation}

The data recorded by the GPS receivers were first filtered to remove locations at the colony within a buffer radius of $2 \mathrm{~km}$. This buffer was used to account for circling and rafting behavior close to the colony at sunset before the birds return to their nest at night. A total of 171 trips from 74 birds were obtained; 38 trips were incomplete, of which 11 could still be used to assess maximum range and foraging areas because it was obvious that the GPS stopped working during the return journey. The remaining incomplete trips were not used in spatial analyses, but because the nests were monitored at least every $2 \mathrm{~d}$, it was still possible to obtain an approximate return date for all individuals. Thus, we were able to classify all trips into 2 categories: short ( $\leq 3 \mathrm{~d}$ ) or long ( $>3 \mathrm{~d}$ ). This distinction was chosen based on trip duration distribution (see Results) and because this dual foraging strategy alternating short and long foraging trips is commonly observed in shearwaters (Granadeiro 
Table 1. Colony size, experimental details and summary statistics for wedge-tailed shearwaters from 4 colonies in New Caledonia, equipped with GPS receivers during the breeding season

\begin{tabular}{|c|c|c|c|c|}
\hline & Pindaï & Temrock & Canards & Mato \\
\hline Colony size (breeding pairs) & 11700 & 11000 & 340 & 2000 \\
\hline \multicolumn{5}{|l|}{ Experimental details } \\
\hline Study period & 6-27 Mar 2017 & 25 Feb-14 Mar 2014 & 13-25 Apr 2017 & 30 Mar-15 Apr 2017 \\
\hline Duration of tracking period (d) & 22 & 18 & 13 & 18 \\
\hline No. GPS receivers deployed & 39 & 43 & 12 & 27 \\
\hline No. GPS receivers recovered & 37 & 35 & 12 & 21 \\
\hline GPS receiver type & $\begin{array}{c}\text { Axytrek, Ecotone, } \\
\text { Pathtrack }\end{array}$ & i-gotU & Lotek, Pathtrack & $\begin{array}{l}\text { Axytrek, Ecotone, } \\
\text { Lotek, Pathtrack }\end{array}$ \\
\hline Sampling interval (min) & $10-60$ & $3-12$ & $20-30$ & $10-15$ \\
\hline Weight ratio GPS receiver/bird (\%) & $1.2-3.9$ & $3.2-5.3$ & $1.4-1.8$ & $1.2-4.2$ \\
\hline \multicolumn{5}{|l|}{ Summary statistics } \\
\hline No. of foraging trips & 81 & 45 & 16 & 29 \\
\hline No. of complete trips & 61 & 36 & 13 & 23 \\
\hline No. of short trips & 37 & 29 & 7 & 11 \\
\hline No. of long trips & 24 & 7 & 6 & 12 \\
\hline Trip duration $($ mean $\pm \mathrm{SD} ; \mathrm{d})$ & $3.75 \pm 3.6$ & $1.73 \pm 1.3$ & $3.42 \pm 2.9$ & $3.44 \pm 2.5$ \\
\hline
\end{tabular}

et al. 1998), including WTS (Congdon et al. 2005, McDuie et al. 2015).

To deal with the heterogeneity of the data provided by different GPS devices and different GPS fix rates (between 3 and $60 \mathrm{~min}$, mean \pm SD $18.2 \pm 14.2 \mathrm{~min}$ ), all tracks were resampled at a regular interval of 30 min using the function redisltraj of the R package adehabitatLT (Calenge 2006). Large gaps of more than $1.5 \mathrm{~h}$ due to limitation in solar battery capacity were not interpolated; the mean \pm SD duration of large gaps $>1.5 \mathrm{~h}$ was $6.6 \pm 8.3 \mathrm{~h}$, with very large gaps generally at night or during return trips. We also calculated the following metrics for all trips: (1) cumulative distance travelled between all locations assuming straight-line Euclidean distances, (2) maximum distance from the colony (hereafter 'maximum range') and (3) average travel speed. Day/night information was calculated from solar elevation using civil twilight common acceptance of $-6^{\circ}$ below horizon, using the $\mathrm{R}$ package tripEstimation (Sumner et al. 2009, Sumner \& Wotherspoon 2016).

\subsubsection{Environmental variables}

To each GPS location, we associated the bathymetry and bathymetry gradient (ETOPO1 1 Arc-Minute Global Relief Model) downloaded from the NOAA website (https://data.nodc.noaa.gov) using the $\mathrm{R}$ package marmap (Pante \& Simon-Bouhet 2013) and the sea surface temperatures (SST) and net primary production $\left(\mathrm{NPP} ; \mathrm{mg} \mathrm{m}^{-2} \mathrm{~d}^{-1}\right.$ ) with $0.25^{\circ}$ resolution (GLOBAL_REANALYSIS_BIO_001_029, Copernicus Marine Environment Monitoring Service, http://marine.copernicus.eu). These 4 variables are commonly used to describe seabird habitats (Wakefield et al. 2009).

\subsubsection{Behaviour classification}

We used the expectation maximization binary clustering (EMBC) method (implemented in the R pack-

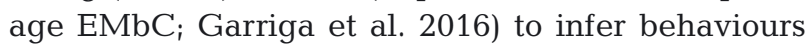
from the GPS tracks. This algorithm, based on Gaussian mixture model maximum likelihood, classified 4 different movement types based on 2 input variables: travel speed, and turning angle between subsequent locations, where both parameters were calculated using loxodromic distances and bearings. Assuming that wide turning angles between locations (arearestricted search, ARS) were associated with foraging behaviour, while fast and straight bouts were typical of directed commuting movements (Garriga et al. 2016), we assigned the following behaviour labels to the movement clusters: travelling-commuting or directed movement (high-speed low turn, HL), resting on the water (low-speed low turn, LL), and intensive (low-speed high turn, LH) and extensive searching (high-speed high turn, HH) (Louzao et al. 2014, Garriga et al. 2016). We considered intensive and extensive search modes represented small- and large- 
scale ARS, respectively (Weimerskirch et al. 2007). This method required few prior assumptions and it has been used to interpret ecologically meaningful behaviours from movement data for a range of seabird species including procellariiforms (de Grissac et al. 2017, Mendez et al. 2017, Bennison et al. 2018, Clay et al. 2019).

\subsubsection{Localization of foraging areas and overlaps}

For each individual, we computed and mapped the utilization distribution (UD) using a fixed kernel density estimation (KDE) of the GPS locations classified as 'foraging' with a smoothing parameter $\left(h=0.2^{\circ}\right)$ to avoid over-fragmentation and a grid of $0.1 \times 0.1^{\circ}$ cells. Because in each colony a few individuals were tracked for several short trips (2 to 4), we checked for pseudoreplication using the method described in Lascelles et al. (2016) and in Supplement 1 (Text S1, Table S1, see www.int-res.com/articles/suppl/m633p225_supp.pdf). No individual was tracked for more than one long trip. To quantify the magnitude of the spatial overlap between the individuals belonging to the 4 different colonies, we used a randomization procedure following Cecere et al. (2018) and detailed in Supplement 2 (Text S2). First, an overlap matrix of all the individual UDs from all colonies was built. The UD overlap between pairs of individuals $i$, $j$ was calculated using the utilization distribution overlap index (UDOI; Fieberg \& Kochanny 2005). UDOI values range from 0 (no overlap) to 1 (uniformly distributed and have $100 \%$ overlap; but can be $>1$ when UDs are non-uniformly distributed). We then built a second matrix where each pair of individuals $(i, j)$ was coded as 0 if both individuals belonged to the same colony, and 1 if they belonged to different colonies. We calculated the correlation coefficient $r_{\text {obs }}$ (Pearson's $r$ ) between the 2 matrices. Because of the coding of colony membership, highly negative values of $\mathrm{r}_{\mathrm{obs}}$ indicate that (1) foraging areas (UD) of individuals belonging to the same colony are highly overlapping, and (2) those of individuals belonging to different colonies are segregated. We then repeated the same procedure 5000 times but with randomly rotated individual tracks (anchored to colony coordinates and considering land barrier). By this randomization bootstrap procedure, we obtained a distribution of r-values representing the null hypothesis of random spatial distribution of UDs around the colonies and we could calculate the probability ( $p_{\text {rand }}$ ) that $r_{\text {rand }}$ was more negative than $r_{\text {obs }}$ (i.e. a very small $p_{\text {rand }}$ indicate that the UDs of individuals from different colonies were more segregated than random). We used the same procedure to quantify segregation between and within pairs of neighbouring colonies Pindaï/Temrock and Canards/Mato. For clarity, we show only the maps of the UDs in the Results, but all the results of the randomization procedures are provided in Supplement 2 (Figs. S1-S4). As only a fraction of each colony was tracked, we also assessed the representativeness of the track samples following the method described in Lascelles et al. (2016) (see also Cecere et al. 2018) and summarized in Supplement 3 (Text S3, Fig. S5). Representativeness was $>95 \%$ for both long- and short-trip pools of all colonies except Canards, for which the sample size was too small. Results including the colony Canards are therefore to be considered with caution.

Kernel analyses were performed with the package adehabitatHR (Calenge 2006). All analyses were conducted in R 3.5.1 (R Core Team 2018). Maps were produced using R and QGIS 3.2 (QGIS Development Team 2018).

Statistical analyses were performed under the $\mathrm{R}$ environment and using Statistica 12.0 (Statsoft). Tests were 2-tailed, and the presented values are given as means \pm SD unless stated otherwise. Because some individuals were tracked for several successive trips (minimum of 1 to maximum of 5 trips per individual), and each trip was segmented into a string of many short legs, we analyzed the data on the characteristics of the trips and oceanographic conditions for each leg using mixed-model ANOVAs to avoid problems linked with pseudo-replication. Depth, slope, SST and NPP were the dependent variables, categories (colony, day/night, type of behavior) were entered as fixed factors and individual was considered as a random factor. Values for variables representing percentage were arcsine-transformed before performing ANOVAs. Due to the small sample size for some colonies, we kept the model simple by estimating a small number of parameters using the data and including no interaction terms

\subsection{Geolocation tracking}

In 2014, between 2 and 10 March, 30 WTS were equipped with global location sensing (GLS) lightimmersion loggers (British Antarctic Survey) at the Temrock colony. In 2017, between 13 March and 12 April, 40 WTS were equipped with MK3005 GLS loggers at Pindaï (20 GLS) and Mato (20 GLS). The GLS loggers were fixed to the leg with a Velcro band in 2014 and with a plastic band in 2017. Breeding birds were equipped when they were leaving their 
burrow after having fed their chick, and the devices were retrieved after 1 or 2 yr. For birds equipped in 2014, 8 loggers were recovered between 26 November and 6 December 2014, and 5 between 28 February and 10 March 2016 (total percent recovered = $43 \%$ ). Several individuals were recaptured during these periods but had lost the loggers. For birds fitted with GLS in 2017, 27 loggers (11 at Pindaï, 16 at Mato) were recovered (68\%) between 25 October 2017 and 24 January 2018.

Of a total of 40 GLS recovered, 35 worked properly and provided data. GLS loggers record sunrise/sunset, thus allowing the calculation of latitude and longitude except during 2-3 wk around equinoxes, when only estimation of longitude is reliable. Bird locations were estimated using the GeoLight and probGLS packages in R (Lisovski \& Hahn 2012). As positions obtained from GLS have a relatively low accuracy (180 km on average; Phillips et al. 2004), we used a conservative approach to filter data with maximum speed and calculate the distance covered. Daily speeds greater than $40 \mathrm{~km} \mathrm{~h}^{-1}$ were excluded since birds spend on average $>80 \%$ of their time sitting on the water (see Results). The dates of nonbreeding and breeding periods were determined by identifying rapid shifts in distance from the colony. Fifty percent (core area) kernel density distributions were calculated with a smoothing parameter $h=$ $180 \mathrm{~km}$ to examine at-sea distribution of WTS during the migratory period using the adehabitatHR package in R (Calenge 2006). Overlap among the kernels from the 3 colonies outside of the breeding period was calculated using the simple Bhattacharyya's affinity index (Fieberg \& Kochanny 2005) that ranges from 0 (no overlap) to 1 (complete overlap). The direction of flight during migration was estimated between the first point and last point of the migratory movement

In addition to light levels, GLS loggers recorded immersion in salt water, allowing the estimation of time spent in flight or sitting on the water. The raw immersion data were either values from 0 (no immersion) to 200 (permanently immersed), indicating the number of $3 \mathrm{~s}$ periods during 10 min blocks when the sensor was immersed in saltwater, or the exact timing of state change (in water or in air). Immersion data were used to estimate the daily percentage of time spent on the sea surface (activity) separately for diurnal and nocturnal periods, based on local sunset and sunrise times derived by analysis of the daylight curves. The mean percentage of time the birds spent sitting on the water (wet) was calculated daily during each period of phenology (breeding, northward migration and inter-breeding) to provide information on seasonal variations in foraging behaviour. Conversely, the time spent dry is generally interpreted as a bird being either on land at the colony or flying, and therefore could be assumed not to be foraging but travelling, at least during the migration and nonbreeding season. The GLS loggers also recorded SST (range $0-60^{\circ} \mathrm{C}$ ) when the logger was immersed for a period of at least 10 to 25 min according to the GLS type. The GLS loggers recovered recorded uninterrupted light data, but the memory was full for the activity and temperature data during the non-breeding period, and thus for most birds, data were not available for the southward migration and during pre-breeding.

Dates and durations of migration were estimated from changes in latitude estimated from the GLS data. Migration was easily detected because it corresponded with a rapid and continuous change in latitude northwards (or southwards for the return phase). Arrival date in the wintering zone was estimated from cessation in the rapid change in latitude.

\section{RESULTS}

\subsection{Breeding season}

\subsubsection{Characteristics of foraging trips}

The distribution of the duration of foraging trips for all colonies combined was bimodal, with numerous $1 \mathrm{~d}$ trips, but also trips lasting 2-3 d up to $5 \mathrm{~d}$, and longer trips from 4 to $13 \mathrm{~d}$ (Fig. 2).

Trip duration was strongly correlated with maximum range (Fig. 3). Short trips of 1-3 d were within $100-150 \mathrm{~km}$ from the colony (mean $97 \pm 77 \mathrm{~km}$ ), and long trips $>3 \mathrm{~d}$ were up to $760 \mathrm{~km}$ from the colony

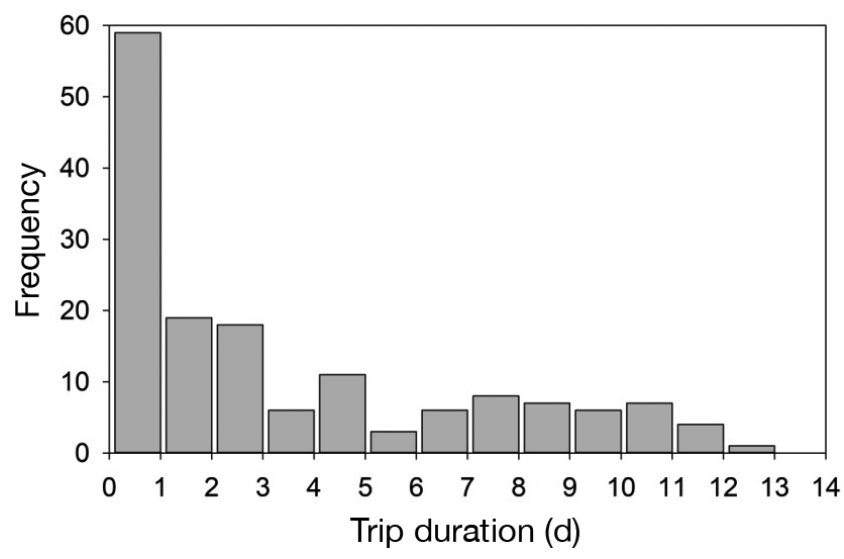

Fig. 2. Distribution of the duration of foraging trips for all colonies combined 


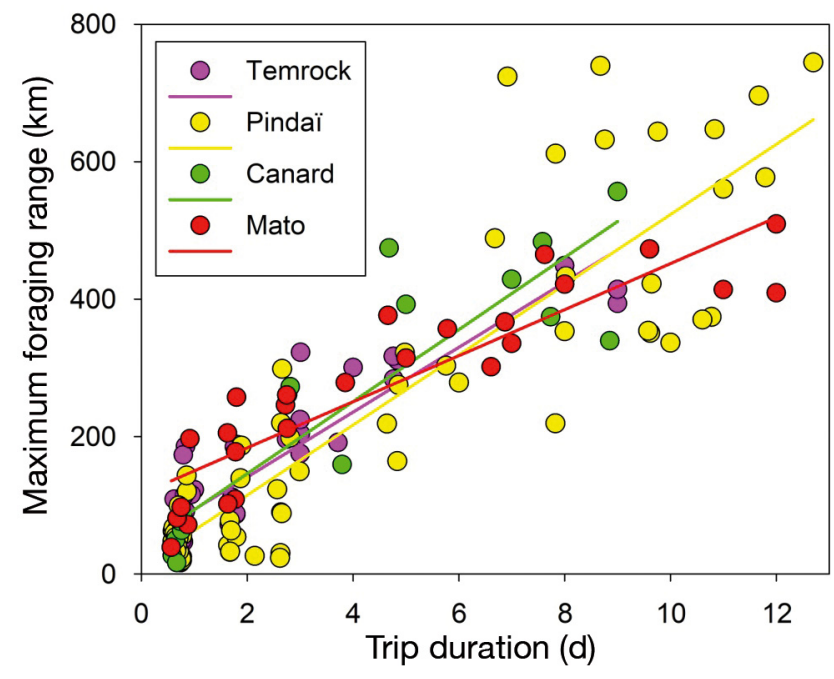

Fig. 3. Relationship between duration of foraging trips and maximum range for the 4 colonies studied in New Caledonia. Regression lines are shown for each colony (mean $398 \pm 153 \mathrm{~km}$ ). Considering all 1-3 d trips as short trips in duration and range, the distribution of short and long trips among the 4 colonies was not significantly different $\left(\chi^{2}{ }_{3}=5.9, p=0.112\right)$. Whereas trip duration did not differ among colonies (Kruskal-Wallis test, $H_{3,155}=4.5, \mathrm{p}=0.212$ ), trips differed in maximum foraging range only between 2 colonies $\left(F_{3,151}=\right.$ $2.7, p=0.045$ ), and on average were longer for Mato birds than for Temrock birds.

Trips consisted of commuting segments interspersed with searching segments where birds changed direction rapidly, showing stereotypical ARS behaviour (Fig. 4). Using EMBC, based on speed and direction, we distinguished 4 behavioural categories (Figs. 4,5). The proportions of these behaviours were not significantly different between short and long trips $\left(\chi^{2}{ }_{3}=4.2, \mathrm{p}=0.152\right)$, but differed significantly between day and night $\left(\chi^{2}{ }_{3}=48.6\right.$, $\mathrm{p}<0.001)$. At night, birds spent extended periods resting at the surface, and lesser amounts travelling and searching intensively; during the day, resting was infrequent and birds spent most time travelling and searching intensively (Fig. 5).

\subsubsection{Foraging zones}

WTS from the 4 colonies foraged all around New Caledonia (Fig. 6). During short trips there was much overlap between the foraging zones of the birds from the 2 neighbouring colonies Pindaï and Temrock $\left(\mathrm{r}_{\mathrm{obs}}=-0.004\right.$, $\mathrm{p}_{\text {rand }}=0.793$; Fig. 7A and Fig. S3), but the 2 colonies Canards and Mato were significantly more spatially segregated than expected by chance according to UDOI values $\left(\mathrm{r}_{\mathrm{obs}}=-0.33\right.$, $\mathrm{p}_{\text {rand }}<0.0001$; Fig. 7 A and Fig. S3). The UDs of individuals from eastern colonies (Pindaï/ Temrock) were highly segregated from that of the southern colonies (Canards/Mato) $\quad\left(\mathrm{r}_{\mathrm{obs}}=-0.52, \quad \mathrm{p}_{\mathrm{rand}}<\right.$ 0.0001; Fig. S2). During longer trips, overlap was less between the 2 colonies of the north (Pindaï and Temrock) but still not significantly different than expected by chance $\left(\mathrm{r}_{\mathrm{obs}}=-0.04\right.$, $\mathrm{p}_{\text {rand }}=$ 0.165; Fig. S4) with Pindaï individuals venturing further than Temrock individuals. The colonies of the southern lagoon (Mato and Canards) showed

Fig. 5. Proportion of the different behaviours during foraging trips during the day and at night. See Fig. 4 for definitions 


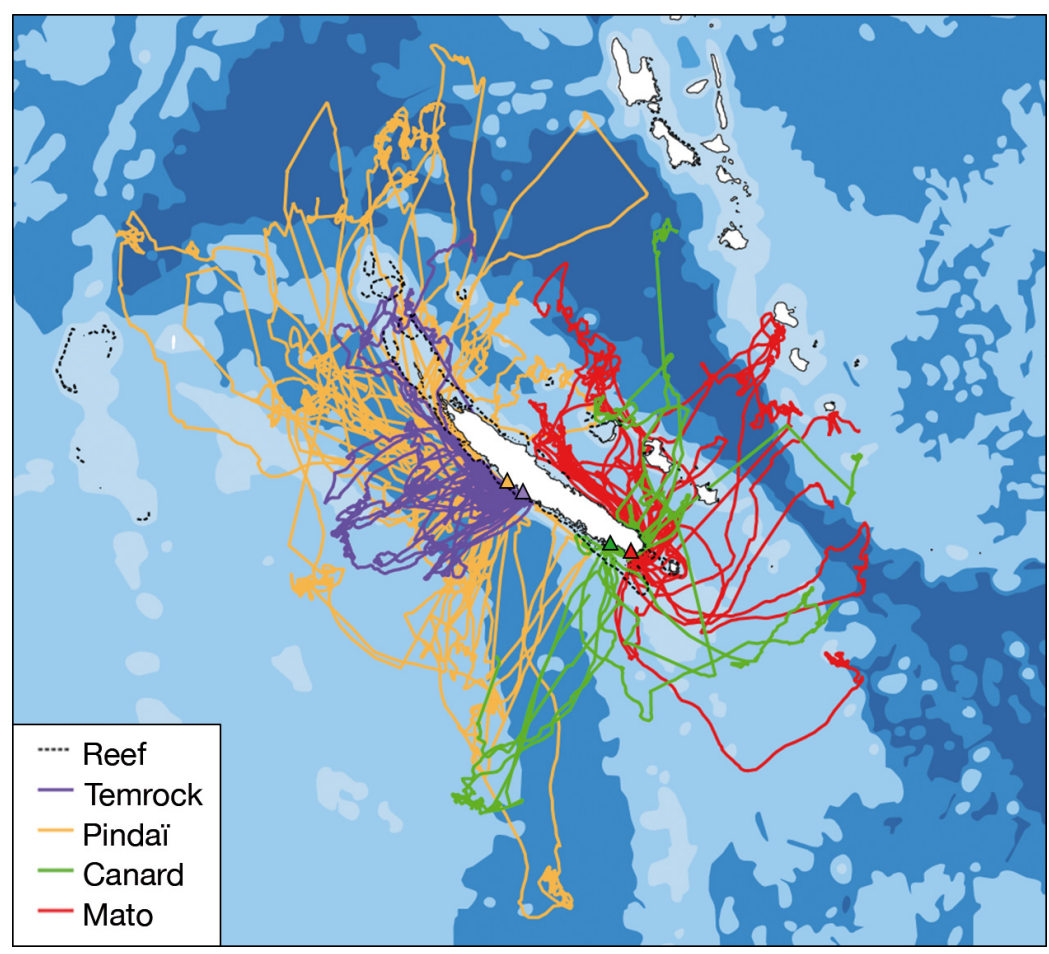

Fig. 6. Foraging trips of GPS-tracked WTS from 4 colonies in New Caledonia superimposed on a bathymetric map of the eastern Coral Sea

\subsubsection{Habitats}

During short trips $\leq 1 \mathrm{~d}$, WTS foraged in the vicinity of their colony. Pindaï and Temrock birds foraged mainly over deep waters $(>250 \mathrm{~m}$ depth), and transited over the lagoon and reef for very short periods during commuting flights to and from the colony, as indicated by the infrequent occurrence of locations at depths shallower than $250 \mathrm{~m}$ (Fig. 8). Upon their return to the colony, birds flew along the outer length of the fringing reef. Conversely, during short trips, birds from the Mato and Canards colonies foraged over shallower waters at the edge of the extensive southern lagoon of New Caledonia (Fig. 8). During long trips, birds from all colonies foraged over deep oceanic waters mainly between 2000 and $4000 \mathrm{~m}$ depth (Fig. 8). During short trips of 2-3 d, birds foraged over both shallow and deep waters.

During short trips, WTS foraged

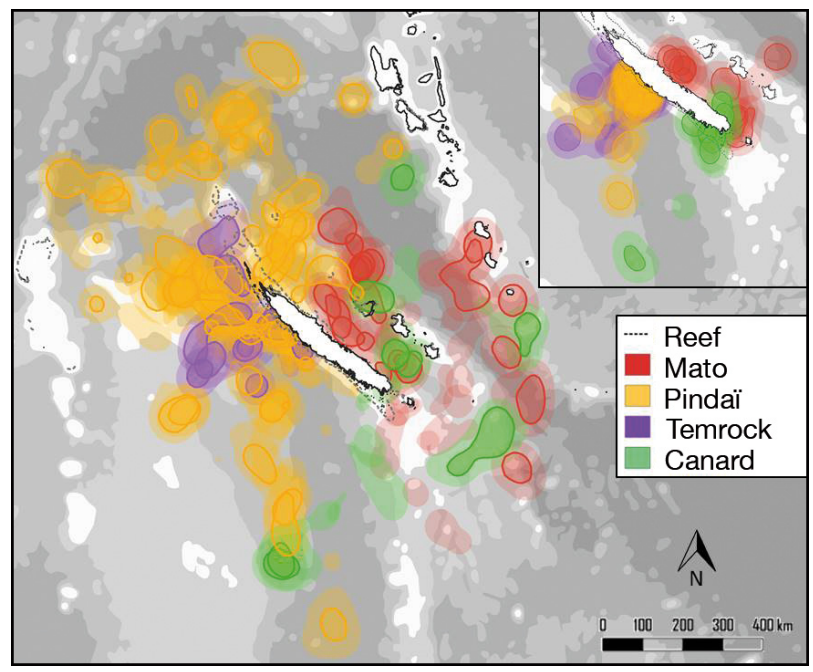

Fig. 7. Kernel distribution $(90 \%, 50 \%)$ of GPS-tracked WTS from 4 colonies in New Caledonia during foraging (main figure for long trips, inset for short trips)

very little overlap as during short trips $\left(\mathrm{r}_{\mathrm{obs}}=-0.13\right.$, $p_{\text {rand }}=0.008$; Fig. 7 and Fig. S4). There was almost no overlap between individuals from the northern and southern colonies $\left(\mathrm{r}_{\mathrm{obs}}=-0.20, \mathrm{p}_{\text {rand }}<0.0001\right)$ : the former ranged to the northwest and the latter ranged to the southern part of New Caledonia (Fig. 7B and Fig. $\mathrm{S} 2)$. over shallower waters with steeper slopes compared to long trips $\left(F_{1,70}=16.3, \mathrm{p}<0.001\right.$ and $F_{1,7}=25.4$, $\mathrm{p}<0.001)$. NPP was higher $\left(F_{1,70}=14.9, \mathrm{p}=0.004\right.$ and $F_{1,70}=16.3, \mathrm{p}<0.001$ ) but SST was similar $\left(F_{1,70}=2.3, \mathrm{p}=0.07\right)$. The zone of active foraging during short trips was more productive than during long trips $\left(F_{1,70}=7.5, \mathrm{p}=0.001\right)$, and differed between colonies, with birds from the Canards colony foraging in more productive waters during short trips $\left(F_{3,50}=28.7, \mathrm{p}<0.001\right)$, but not during long trips $\left(F_{3,33}=1.9, \mathrm{p}=0.145\right)$. Productivity was similar during active foraging and travelling during short trips $\left(F_{1,53}=1.2, \mathrm{p}=0.269\right)$, but was slightly higher during travelling compared to active foraging $\left(F_{3,36}=5.3, \mathrm{p}=0.0267\right)$.

\subsection{Non-breeding season}

All WTS from the 3 colonies migrated to the north of New Caledonia and wintered north of the equator in a wide longitudinal band (Figs. 9, 10). Departure from colonies was on 13 May $\pm 12 \mathrm{~d}$ (range 8 April-24 May), and birds returned to New Caledonia on 24 October \pm 17 d (range 24 August-6 November). Migration dates were not different among colonies $(p>0.4$ for departure 

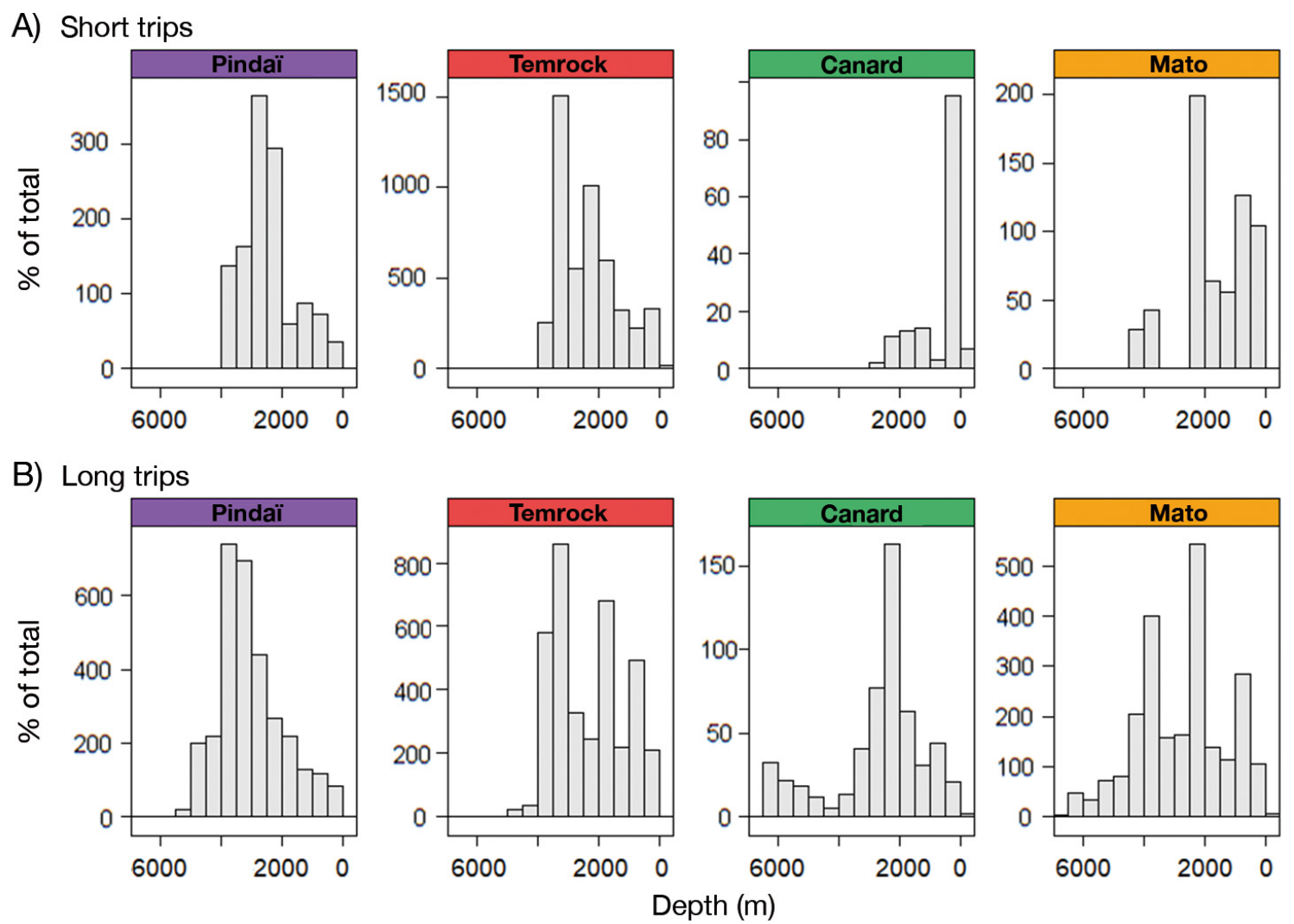

Fig. 8. Distribution of water depths foraged over during (A) short and (B) long trips by WTS from the 4 colonies

and return dates). The northward migratory movement lasted $16.4 \pm 7.1 \mathrm{~d}$, and was shorter than the southward movement, which lasted $23.5 \pm 13.0 \mathrm{~d}$ (paired-sample test, $Z=2.0, \mathrm{p}=0.042$ ). During the northward movement, the duration of migration decreased with departure time: birds leaving New Caledonia early took more time to reach wintering grounds than birds leaving later $\left(F_{1,37}=5.9, \mathrm{p}=\right.$ 0.0022). The northward movement was directed north-eastward for most birds (85\%) with the others taking a more northward direction, with some birds moving as far east as the longitude of the Hawaiian Islands (Fig. 9). Throughout the wintering period, all birds had a slow westward movement before returning to New Caledonia (Fig. 9). Two birds from Temrock were tracked for 2 successive seasons; across years, the tracks were similar for both birds.

Overlap among wintering zones was extensive (Fig. 9), with Bhattacharyya's affinity values of $78 \%$ for Pindaï and Temrock, $83 \%$ for Pindaï and Mato, and $87 \%$ for Temrock and Mato; overlap with Heron Island was less (Fig. 9).

SST recorded by GLS loggers indicated that birds moved from the relatively cooler waters off New
Caledonia $\left(\mathrm{SST}=26.7 \pm 0.3^{\circ} \mathrm{C}\right)$ to warmer waters when crossing the equator $\left(29.1 \pm 0.8^{\circ} \mathrm{C}\right)$ and in their wintering areas $\left(28.6 \pm 0.9^{\circ} \mathrm{C}\right)\left(F_{2,7}=15.7, \mathrm{p}<\right.$ $0.0001)$. In the wintering areas, average SST differed extensively between individuals, ranging from 27.7 to $29.8^{\circ} \mathrm{C}\left(F_{5,2895}=1230, \mathrm{p}<0.001\right)$, because some birds remained along the equator, while others moved as far north as $20^{\circ} \mathrm{N}$ (Fig. 9). WTS wintered over deeper waters than during breeding $\left(F_{4,11}=\right.$ 57.9, p $<0.0001$; Fig. 10, Table 2), and in warmer waters compared with breeding. They encountered the warmest water while crossing the equator $\left(F_{4,11}=\right.$ 29.0, p $<0.0001$; Table 2).

Considering the entire breeding cycle, chlorophyll a concentration was low (0.05-0.08 $\left.\mathrm{g} \mathrm{m}^{-3}\right)$ throughout the year, lower during the winter and slightly higher during the breeding season $\left(F_{4,11}=6.1, \mathrm{p}=0.0005\right.$; Table 2).

During the wintering phase, birds spent the majority of time sitting on the water, especially at night, compared with migration and the chick-rearing period off New Caledonia, when they spent more time in flight (Table 2). However, the take-off rate (landing and transition to flight) was very similar during these 3 phases (Table 2). 


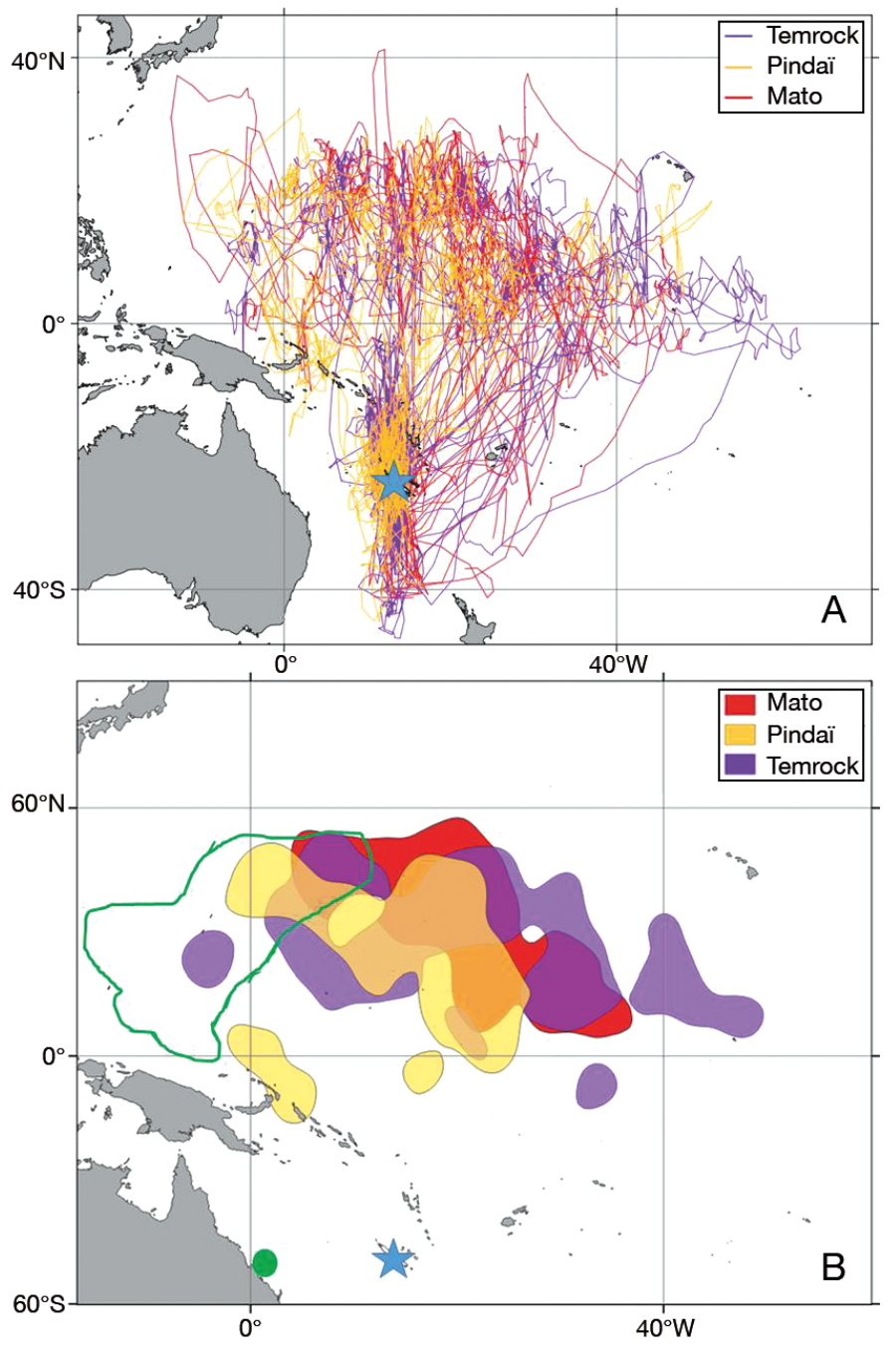

Fig. 9. (A) Movement of WTS from 3 colonies in New Caledonia (blue star) during the non-breeding season. Birds were tracked by GLS loggers. (B) Kernel distribution (50\%) of WTS from 3 colonies in New Caledonia. Green perimeter: $50 \%$ kernel distribution of birds breeding on Heron Island, Great Barrier Reef (green dot) (McDuie \& Congdon 2016)

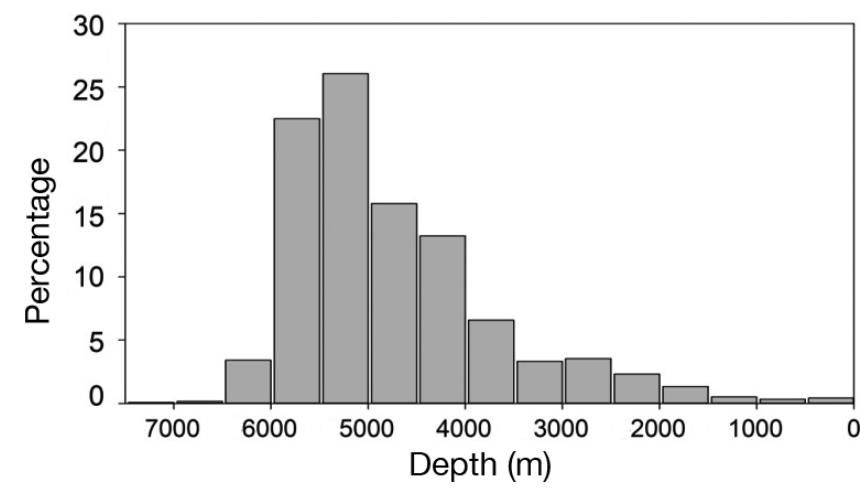

Fig. 10. Depth distribution of the waters where WTS from 3 colonies in New Caledonia occur during the non-breeding season

\section{DISCUSSION}

\subsection{Breeding season}

When rearing chicks, WTS from New Caledonia used a bimodal strategy whereby they undertook either short trips close to the colony, or long trips to distant areas. There was no significant difference in trip duration among colonies, although Mato birds tended to make longer trips, and Temrock birds performed a greater proportion of short trips. However, the Temrock colony was studied in a year (2014) different from the 3 other colonies (2017), and it is possible that environmental and trophic conditions vary across years. In fact, the trade winds characterizing austral summer around New Caledonia were significantly stronger in 2014, inducing stronger ocean mixing and evaporative cooling. Accordingly, SSTs were significantly warmer in 2017 than in 2014. The amplitude and structure of primary production patterns also changed between 2014 and 2017, and were not correlated with SST patterns as classically found in the region during austral summer (Menkès et al. 2015). In addition, in such oligotrophic waters, it is likely that primary production is a poor index for the biomass on which seabirds prey and may not be a useful index for food production. However, the fact that there were not pronounced differences in foraging trips between years suggests that the range of variability observed was not sufficient to cause changes in foraging behaviour.

Sample sizes for the Mato colony were small, so apparent differences among colonies require additional study. Differences between years could be due to less abundant or accessible near-colony food resources during some years forcing the birds to use a bimodal strategy when conditions are poorer; such year effects have been observed in WTS elsewhere (Miller et al. 2018) and also in other shearwater species (Granadeiro et al. 1998). Importantly, WTS from colonies on the Great Barrier Reef consistently use only a dual foraging strategy (Congdon et al. 2005, McDuie et al. 2015, Miller et al. 2018), while limited studies during few seasons at other colonies indicated they performed only short trips (Baduini 2002, Congdon et al. 2005, McDuie et al. 2015). Thus, our findings for New Caledonian WTS confirm that throughout its distribution during the breeding period, this species displays colony-specific differences in foraging behaviour that appear to be linked to local food availability. Similar intra-specific differ- 
Table 2. Activity and oceanographic conditions encountered by WTS around the breeding grounds and during the migration and non-breeding phases. SST: sea surface temperature. Data are means \pm SD (range); -: no data

\begin{tabular}{|c|c|c|c|c|c|}
\hline Parameter & Chick-rearing & $\begin{array}{c}\text { Migration } \\
\text { northwards }\end{array}$ & Wintering & $\begin{array}{l}\text { Migration } \\
\text { southwards }\end{array}$ & Pre-breeding \\
\hline$\%$ Time on water & $\begin{array}{l}31.4 \pm 6.2 \\
(19.1-42.0)\end{array}$ & $\begin{array}{l}41.3 \pm 14.0 \\
(12.2-63.3)\end{array}$ & $\begin{array}{l}70.8 \pm 6.1 \\
(50.9-77.2)\end{array}$ & - & - \\
\hline$\%$ Time on water during day & $\begin{array}{l}28.3 \pm 6.1 \\
(20.3-41.6)\end{array}$ & $\begin{array}{l}38.9 \pm 9.0 \\
(23.2-53)\end{array}$ & $\begin{array}{l}59.7 \pm 4.7 \\
(51.8-68.7)\end{array}$ & - & - \\
\hline$\%$ Time on water at night & $\begin{array}{l}30.7 \pm 10.3 \\
(16.3-56.7)\end{array}$ & $\begin{array}{l}44.3 \pm 16.7 \\
(14.1-70.7)\end{array}$ & $\begin{array}{l}84.0 \pm 6.0 \\
(70.6-92.2)\end{array}$ & - & - \\
\hline Take-off rate $\left(\mathrm{h}^{-1}\right)$ & $7.2 \pm 1.8$ & $6.7 \pm 2.0$ & $7.0 \pm 2.0$ & - & - \\
\hline $\operatorname{SST}$ GLS $\left({ }^{\circ} \mathrm{C}\right)^{\mathrm{a}}$ & $27.0 \pm 0.5$ & $29.1 \pm 0.7$ & $28.7 \pm 0.8$ & 29.9 & 24.8 \\
\hline SST satellite $\left({ }^{\circ} \mathrm{C}\right)^{\mathrm{b}}$ & $24.8 \pm 2.9$ & $29.6 \pm 0.7$ & $28.9 \pm 0.9$ & $27.6 \pm 2.2$ & $27.1 \pm 1.9$ \\
\hline Ocean depth (m) & $-2928 \pm 1151$ & $-4769 \pm 976$ & $-4768 \pm 1097$ & $-3768 \pm 1268$ & $-3140 \pm 1344$ \\
\hline Chlorophyll a ( $\left.\mathrm{g} \mathrm{m}^{-3}\right)$ & $0.079 \pm 0.057$ & $0.07 \pm 0.032$ & $0.052 \pm 0.04$ & $0.062 \pm 0.041$ & $0.057 \pm 0.048$ \\
\hline
\end{tabular}

ences have been found in other species of shearwater (Weimerskirch et al. 1994, Granadeiro et al. 1998, Baduini \& Hyrenbach 2003).

Dual foraging strategies are assumed to be used by species, or populations, as a means of overcoming limitations associated with insufficient near-colony resource availability (Weimerskirch et al. 1994, Baduini \& Hyrenbach 2003). As with other tropical populations, WTS in New Caledonia forage in oligotrophic near-colony waters. However, colony sizes in New Caledonia are exceptionally large, with potential for competition among individuals from colonies in relatively close proximity (i.e. within the mean foraging range). Therefore, the dual foraging strategy observed in New Caledonia might be especially influenced by strong intra-specific competition (Furness \& Birkhead 1984, Lewis et al. 2001), as much as by poor local productivity. The maximum range of New Caledonia birds during long trips reaches $819 \mathrm{~km}$, whereas it was $670 \mathrm{~km}$ at Heron Island, $495 \mathrm{~km}$ in subtropical waters (Miller et al. 2018) and only $200 \mathrm{~km}$ in the Indian Ocean (Cecere et al. 2013). This is consistent with the hypothesis that the oligotrophic environment combined with large population sizes and intense competition may indeed lead New Caledonian birds to forage farther during their long trips.

WTS forage over a wide sector around New Caledonia. In our study, the 2 pairs of colonies were $\sim 200 \mathrm{~km}$ apart, with the northernmost colonies foraging to the west and the southern colonies to the east. This resulted in a clear segregation of the foraging zones between the 2 groups of colonies. However, within each region, the foraging zones of the 2 colonies overlapped extensively, especially during short trips. The northernmost colonies, Pindaï and Temrock, are located adjacent to a narrow reef and are close to the shelf edge. Birds from both of these colonies forage over deep waters during short and long trips, with little time spent over shallow waters. In contrast, the 2 southern colonies are located at the inner edge of a large reef and lagoon at the southern end of New Caledonia. Birds from these colonies spent most of their time foraging over shallower waters during short trips, but over deep waters during longer trips. In seabirds, segregation between colonies is a widespread phenomenon, and overlap occurs generally in highly productive areas (Bolton et al. 2019). Most studies reported in the review of Bolton et al. (2019) concern non-tropical waters. Comparatively few studies exist for tropical seabirds. Our study suggests that overlap during short trips is extensive, but that segregation occurs during long trips. These differences indicate that long trips, during which adults regain body mass (McDuie et al. 2015), are probably performed in the most favourable habitat for WTS, that is, deep oceanic waters. Conversely, when primarily provisioning the chick during short trips, birds probably use a sub-optimal habitat over shelf waters, a pattern that the WTS has in common with other tubenose species (Baduini \& Hyrenbach 2003). However, the 2 large northern colonies show a significant overlap, which may be associated with zones of enhanced prey availability.

During their foraging trips, especially long trips, WTS move rapidly to foraging zones that are located 
at the maximum range for the trip. These typical commuting trips to 1 or 2 foraging zones are performed during both short and long trips. The ARS zones are mainly over deep oceanic waters, and are not more productive than the areas where WTS travel, suggesting that ARS does not take place in more productive areas as observed for many non-tropical seabird species (Weimerskirch 2007). WTS are known to associate with sub-surface predators when feeding (Au \& Pitman 1986, Jaquemet et al. 2004), and their foraging activity has been clearly linked to predicted tuna distributions in the western Coral Sea (Miller et al. 2018). Therefore, these ARS zones may be related to associations with tuna.

When at sea, foraging activities were more frequent during the day compared with at night. The resting periods were short during the day, most of the time being spent commuting to the foraging zones, and actively foraging at small and large scales. Conversely, at night WTS spent large proportion of their time resting at the surface. Similar results have been found in the Indian Ocean (Catry et al. 2009b). These results suggest that WTS feed mostly during the day; this is in accordance with what is known of the foraging behaviour of shearwaters that are diurnal, visual foragers (Warham 1990), and with the possible association with subsurface predators. In addition, WTS dive frequently and reach depths of $10 \mathrm{~m}$ for feeding (Peck \& Congdon 2006), and this behaviour can probably be performed only during the daytime.

\subsection{Migration and wintering}

Similar to WTS from Heron Island on the Great Barrier Reef (McDuie \& Congdon 2016), New Caledonian birds make a trans-equatorial migration in the Pacific Ocean. This is in contrast with Indian Ocean WTS, which stay south (Western Australia; Surman et al. 2018) or around the equator (Seychelles; Catry et al. 2009b). Our study indicates that birds from New Caledonia winter in a zone different to that used by birds from Heron Island, albeit with marginal overlap (a single individual; Fig. 10). New Caledonian birds disperse to the equatorial and north tropical latitudes north and east of New Caledonia, whereas Heron Island birds concentrate in the equatorial and tropical zone north of New Guinea (Fig. 10). New Caledonian birds start migration $1 \mathrm{wk}$ earlier and return $1 \mathrm{wk}$ earlier compared to Heron Island birds (McDuie \& Congdon 2016). The migration duration and time spent on the wintering grounds are similar between the popu- lations from these 2 breeding sites. Both populations take a northeast bearing when migrating north, likely an optimal response to the direction of the trade winds. While in their wintering zone, New Caledonian birds move progressively west. Heron Island birds do not display this behaviour. During the winter, New Caledonian birds spent an extended period along the equator, a likely response to the absence of wind. In the absence of wind, birds sit on the water. This may coincide with moulting, a period when energy requirements are lower (Cherel et al. 2016).

In contrast with the Indian Ocean, where WTS winter in different sectors dispersed over the entire oceanic basin (Catry et al. 2009b) or a wide sector (Surman et al. 2018), New Caledonian birds from 3 different colonies have very similar movements, and winter in a well-delimitated sector of the Pacific Ocean north of the equator. In this respect, Heron Island birds behave similarly to New Caledonian birds (McDuie \& Congdon 2016). The difference between Indian and Pacific WTS might be due to the inability of Indian Ocean birds to make a trans-equatorial migration because of the presence of the continental mass of Asia, apart from migrating into either the Gulf of Bengal or the Arabian Sea. Alternatively, Indian Ocean populations may find suitable resources in the equatorial zone or in the southern hemisphere yearround. Making a trans-equatorial migration allows birds breeding in the Pacific to encounter a permanent summer season (Shaffer et al. 2006) and to have associated favourable conditions similar to those exploited during the breeding season. However, in the case of WTS, since they spend the non-breeding season in the equatorial Pacific Warm Pool, which is known to be a low-productivity area, the most important factor could be the possible association with tuna throughout the year. Conversely, Indian Ocean birds may have to disperse over wider oceanic surface. Migration strategies similarly different between the Pacific and Indian Oceans have been observed in 2 populations of the south polar skua Catharacta antarctica breeding in Antarctica: the population from the Pacific makes a trans-equatorial migration to sub-Arctic waters, the other from the Indian Ocean migrates to the tropical waters of the Indian Ocean (Weimerskirch et al. 2015).

\subsection{Conclusions}

WTS forage throughout the year over warm, deep and oligotrophic tropical waters in the northern and southern hemispheres, avoiding spending time over 
the equatorial band. They do not appear to be attracted by specific large-scale oceanographic features like many seabirds and other top marine predators (Veit \& Hunt 1991, Weimerskirch 2007), but more detailed analyses are required to determine whether these populations are attracted to specific meso- or large-scale oceanographic features. This characteristic is also found in other tropical seabirds that share with WTS their close association with sub-surface predators such as tunas and dolphins (Mendez et al. 2017).

The results of this study, compared to the other studies available on the biology and foraging ecology of the WTS, show the flexibility of the foraging and migration strategies of this species. WTS populations appear to be adapted to the local conditions encountered at both breeding and overwintering sites, and have the capacity to cross or not cross the equator to overwinter. This flexibility is probably a reason for the success of this widespread and abundant species, whose breeding sites and foraging zones span all tropical and subtropical waters of the Indo-Pacific. This flexibility at the within-population level is associated with significant differences in morphology, and substantial genetic differentiation between distant populations (Peck et al. 2008). Our findings that the birds from 4 colonies in New Caledonia display very similar foraging behaviour (although with separated foraging zones during breeding) and migratory behaviour suggest the existence of a single homogeneous population.

Acknowledgements. We thank the many field workers involved in the field studies in New Caledonia, especially Ludovic Renaudet and David Ugolini (SCO, Noumea), and Aymeric Bodin, Maële Brisset, Guillaume Chagneau, Julien Dijoux, Hélène de Méringo, Angélique Pagenaud and Aurore Pujapujane. The study was funded by the ERC Program Earlylife to HW, the EU BEST 2.0 project 'Biopelagos', and the Province Nord (convention 15C493) to IRD. We thank James Russell (University of Auckland, NZ) for providing GLS loggers deployed in 2017 in the frame of an ECREA-funded program. Permits to handle birds at Temrock, Mato and Canards were delivered by New Caledonia's Province Sud (permit nos. 609-2014/ARR/DENV, 2903-2015/ ARR/DENV and 2695-2016/ARR/DENV), and at Pindaï, by New Caledonia's Province Nord (permit nos. 161214_AC 2303_2016 and 161214_AC2304_2017). We thank 3 anonymous reviewers for helpful suggestions on an earlier version of the manuscript.

\section{LITERATURE CITED}

Ashmole NP (1963) The regulation of numbers of tropical oceanic birds. Ibis 103:458-473

Ashmole NP (1971) Sea bird ecology and the marine environment. In: Farner DS, King JS, Parkes KC (eds) Avian biology, Vol 1. Academic Press, New York, p 223-286
Au DWK, Pitman RL (1986) Seabird interactions with dolphins and tuna in the Eastern Tropical Pacific. Condor 88:304-317

* Baduini CL (2002) Parental provisioning patterns of wedgetailed shearwaters and their relation to chick body condition. Condor 104:823-831

Baduini CL, Hyrenbach KD (2003) Biogeography of procellariiform foraging strategies: Does ocean productivity influence provisioning? Mar Ornithol 31:101-112

*Bennison A, Bearhop S, Bodey TW, Votier SC and others (2018) Search and foraging behaviors from movement data: a comparison of methods. Ecol Evol 8:13-24

* Bolton M (1995) Experimental evidence for regulation of food delivery to storm petrel, Hydrobates pelagicus, nestlings: the role of chick body condition. Anim Behav 50:231-236

Bolton M, Conolly G, Carroll M, Wakefield ED, Caldow R (2019) A review of the occurrence of inter-colony segregation of seabird foraging areas and the implications for marine environmental impact assessment. Ibis 161: $241-259$

* Calenge C (2006) The package 'adehabitat' for the R software: a tool for the analysis of space and habitat use by animals. Ecol Modell 197:516-519

Catry T, Ramos JA, Jaquemet S, Faulquier L and others (2009a) Comparative foraging ecology of a tropical seabird community of the Seychelles, western Indian Ocean. Mar Ecol Prog Ser 374:259-272

* Catry T, Ramos JA, Le Corre M, Phillips RA (2009b) Movements, at-sea distribution and behaviour of a tropical pelagic seabird: the wedge-tailed shearwater in the western Indian Ocean. Mar Ecol Prog Ser 391: 231-242

Ceccarelli DM, McKinnon AD, Andréfouët S, Allain V and others (2013) The coral sea: physical environment, ecosystem status and biodiversity assets. Adv Mar Biol 66: 213-290

* Cecere JG, Calabrese L, Rocamora G, Catoni C (2013) Movement patterns and habitat selection of wedgetailed shearwaters (Puffinus pacificus) breeding at Aride Island, Seychelles. Waterbirds 36:432-437

Cecere JG, Bondì S, Podofillini S, Imperio S and others (2018) Spatial segregation of home ranges between neighbouring colonies in a diurnal raptor. Sci Rep 8: 11762

Cherel Y, Quillfeldt P, Delord K, Weimerskirch H (2016) Combination of at-sea activity, geolocation and feather stable isotopes documents where and when seabirds molt. Front Ecol Evol 4:3

* Clay TA, Oppel S, Lavers JL, Phillips RA, Brooke MdL (2019) Divergent foraging strategies during incubation of an unusually wide-ranging seabird, the Murphy's petrel. Mar Biol 166:8

Congdon BC, Krockenberger AK, Smithers BV (2005) Dualforaging and co-ordinated provisioning in a tropical Procellariiform, the wedge-tailed shearwater. Mar Ecol Prog Ser 301:293-301

* de Grissac S, Bartumeus F, Cox SL, Weimerskirch H (2017) Early life foraging: behavioural responses of newly fledged albatrosses to environmental conditions. Ecol Evol 7:6766-6778

* Felicísimo ÁM, Muñoz J, González-Solís J (2008) Ocean surface winds drive dynamics of transoceanic aerial movements. PLOS ONE 3:e2928

Fieberg J, Kochanny CO (2005) Quantifying home-range overlap: the importance of the utilization distribution. J Wildl Manag 69:1346-1359 
Furness RW, Birkhead TR (1984) Seabird colony distributions suggest competition for food supplies during the breeding season. Nature 311:655-656

Garriga J, Palmer JRB, Oltra A, Bartumeus F (2016) Expectation-maximization binary clustering for behavioural annotation. PLOS ONE 11:e0151984

Granadeiro JP, Nunes M, Silva MC, Furness RW (1998) Flexible foraging strategy of Coryu's shearwater, Calonectris diomedea, during the chick-rearing period. Anim Behav 56:1169-1176

Jaquemet S, Le Corre M, Weimerskirch H (2004) Seabird community structure in a coastal tropical environment: importance of natural factors and fish aggregating devices (FADs). Mar Ecol Prog Ser 268:281-292

Kascelles BG, Taylor PR, Miller MGR, Dias MP and others (2016) Applying global criteria to tracking data to define important areas for marine conservation. Divers Distrib 22:422-431

Lewis S, Sherratt TN, Hamer KC, Wanless S (2001) Evidence of intra-specific competition for food in a pelagic seabird. Nature 412:816-819

Kisovski S, Hahn S (2012) GeoLight-processing and analysing light-based geolocation in R. Methods Ecol Evol 3:1055-1059

Louzao M, Weigand T, Bartumeus F, Weimerskirch H (2014) Coupling instantaneous energy-budget models and behavioural mode analysis to estimate optimal foraging strategy: an example with wandering albatrosses. Mov Ecol 2:8

McDuie F, Congdon BC (2016) Trans-equatorial migration and non-breeding habitat of tropical shearwaters: implications for modelling pelagic Important Bird Areas. Mar Ecol Prog Ser 550:219-234

McDuie F, Weeks SJ, Miller MG, Congdon B (2015) Breeding tropical shearwaters use distant foraging sites when self-provisioning. Mar Ornithol 43:123-129

McDuie F, Weeks SJ, Congdon BC (2018) Oceanographic drivers of near-colony seabird foraging site use in tropical marine systems. Mar Ecol Prog Ser 589: 209-225

Mendez L, Borsa P, Cruz S, de Grissac S and others (2017) Geographical variation in the foraging behaviour of the pantropical red-footed booby. Mar Ecol Prog Ser 568: 217-230

Menkes CE, Allain V, Rodier M, Gallois F and others (2015) Seasonal oceanography from physics to micronekton in the south-west Pacific. Deep Sea Res II 113:125-144

Miller MGR, Carlile N, Phillips JS, McDuie F, Congdon BC (2018) Importance of tropical tuna for seabird foraging over a marine productivity gradient. Mar Ecol Prog Ser 586:233-249

Pandolfi-Benoit M, Bretagnolle V (2002) Seabirds of the southern lagoon of New Caledonia: distribution, abundance and threats. Waterbirds 25:202-213

Pante E, Simon-Bouhet B (2013) marmap: a package for importing, plotting and analyzing bathymetric and topographic data in R. PLOS ONE 8:e73051

Payri CE, Allain V, Aucan J, David C and others (2019) New Caledonia. In: World seas: an environmental evaluation. Academic Press, London, p 593-618

Peck DR, Congdon BC (2006) Sex-specific chick provision-

Editorial responsibility: Kyle Elliott,

Sainte-Anne-de-Bellevue, Québec, Canada ing and diving behaviour in the wedge-tailed shearwater Puffinus pacificus. J Avian Biol 37:245-251

*Peck DR, Bancroft WJ, Congdon BC (2008) Morphological and molecular variation within an ocean basin in wedgetailed shearwaters (Puffinus pacificus). Mar Biol 153: 1113-1125

* Phillips RA, Xavier JC, Croxall JP (2003) Effects of satellite transmitters on albatrosses and petrels. Auk 120: 1082-1090

* Phillips RA, Silk JRD, Croxall JP, Afanasyev V, Briggs DR (2004) Accuracy of geolocation estimates for flying seabirds. Mar Ecol Prog Ser 266:265-272

QGIS Development Team (2018) QGIS Geographic Information System. Open Source Geospatial Foundation Project

R Core Team (2018) R: a language and environment for statistical computing. R Foundation for Statistical Computing, Vienna

Shaffer SA, Tremblay Y, Weimerskirch H, Scott D and others (2006) Migratory shearwaters integrate oceanic resources across the Pacific Ocean in an endless summer. Proc Natl Acad Sci USA 103:12799-12802

Spear LB, Ainley DG, Walker WA (2007) Foraging dynamics of seabirds in the eastern tropical Pacific Ocean. Stud Avian Biol 35:1-99

Sumner MD, Wotherspoon S (2016) Metropolis sampler and supporting functions for estimating animal movement from archival tags and satellite fixes. R package v.0.0-44. https://cran.r-project.org/package=tripEstimation

* Sumner MD, Wotherspoon SJ, Hindell MA (2009) Bayesian estimation of animal movement from archival and satellite tags. PLOS ONE 4:e7324

* Surman CA, Nicholson LW, Phillips RA (2018) Distribution and patterns of migration of a tropical seabird community in the Eastern Indian Ocean. J Ornithol 159: 867-877

Veit RR, Hunt GL Jr (1991) Broadscale density and aggregation of pelagic birds from a circumnavigational survey of the Antarctic Ocean. Auk 108:790-800

Wakefield ED, Phillips RA, Matthiopoulos J (2009) Quantifying habitat use and preferences of pelagic seabirds using individual movement data: a review. Mar Ecol Prog Ser 391:165-182

Warham J (1990) The petrels. Academic Press, London

* Weimerskirch H (1998) How can a pelagic seabird provision its chick when relying on a distant food resource? Cyclic attendance at the colony, foraging decision and body condition in sooty shearwaters. J Anim Ecol 67:99-109

WWeimerskirch H (2007) Are seabirds foraging for unpredictable resources? Deep Sea Res II 54:211-223

*Weimerskirch H, Chastel O, Ackermann L, Chaurand T, Cuenot-Chaillet F, Hindermeyer X, Judas J (1994) Alternate long and short foraging trips in pelagic seabird parents. Anim Behav 47:472-476

*Weimerskirch H, Pinaud D, Pawlowski F, Bost C (2007) Does prey capture induce area-restricted search? A fine-scale study using GPS in a marine predator, the wandering albatross. Am Nat 170:734-743

Weimerskirch H, Tarroux A, Chastel O, Delord K, Cherel Y, Descamps S (2015) Population-specific wintering distributions of adult south polar skuas over three oceans. Mar Ecol Prog Ser 538:229-237

Submitted: April 15, 2019; Accepted: October 15, 2019 Proofs received from author(s): November 29, 2019 